\title{
Synthesis of Prussian blue-embedded porous polymer for detection and removal of Cs ions
}

Article

Accepted Version

Creative Commons: Attribution-Noncommercial-No Derivative Works 4.0

Namgung, H., Gwon, Y. J., Kim, J., Jang, G., Pepper, S. E., Ogden, M. D., Whittle, K. R., Harwood, L. M. and Lee, T. S. (2018) Synthesis of Prussian blue-embedded porous polymer for detection and removal of Cs ions. Polymer, 158. pp. 320326. ISSN 0032-3861 doi:

https://doi.org/10.1016/j.polymer.2018.11.001 Available at https://centaur.reading.ac.uk/80780/

It is advisable to refer to the publisher's version if you intend to cite from the work. See Guidance on citing.

To link to this article DOI: http://dx.doi.org/10.1016/j.polymer.2018.11.001

Publisher: Elsevier

All outputs in CentAUR are protected by Intellectual Property Rights law, including copyright law. Copyright and IPR is retained by the creators or other copyright holders. Terms and conditions for use of this material are defined in the End User Agreement. 


\section{CentAUR}

Central Archive at the University of Reading

Reading's research outputs online 


\section{Accepted Manuscript}

Synthesis of Prussian blue-embedded porous polymer for detection and removal of Cs ions

Ho Namgung, Young Jin Gwon, Jongho Kim, Geunseok Jang, Sarah E. Pepper, Mark D. Ogden, Karl R. Whittle, Laurence M. Harwood, Taek Seung Lee

\section{的 \\ polymer}

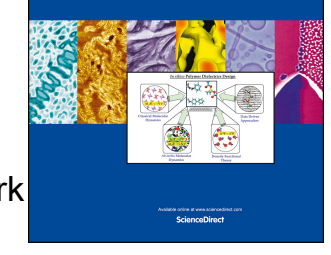

PII:

S0032-3861(18)31019-X

DOI: https://doi.org/10.1016/j.polymer.2018.11.001

Reference: JPOL 21024

To appear in: Polymer

Received Date: 6 September 2018

Revised Date: 18 October 2018

Accepted Date: 1 November 2018

Please cite this article as: Namgung H, Gwon YJ, Kim J, Jang G, Pepper SE, Ogden MD, Whittle KR, Harwood LM, Lee TS, Synthesis of Prussian blue-embedded porous polymer for detection and removal of Cs ions, Polymer (2018), doi: https://doi.org/10.1016/j.polymer.2018.11.001.

This is a PDF file of an unedited manuscript that has been accepted for publication. As a service to our customers we are providing this early version of the manuscript. The manuscript will undergo copyediting, typesetting, and review of the resulting proof before it is published in its final form. Please note that during the production process errors may be discovered which could affect the content, and all legal disclaimers that apply to the journal pertain. 

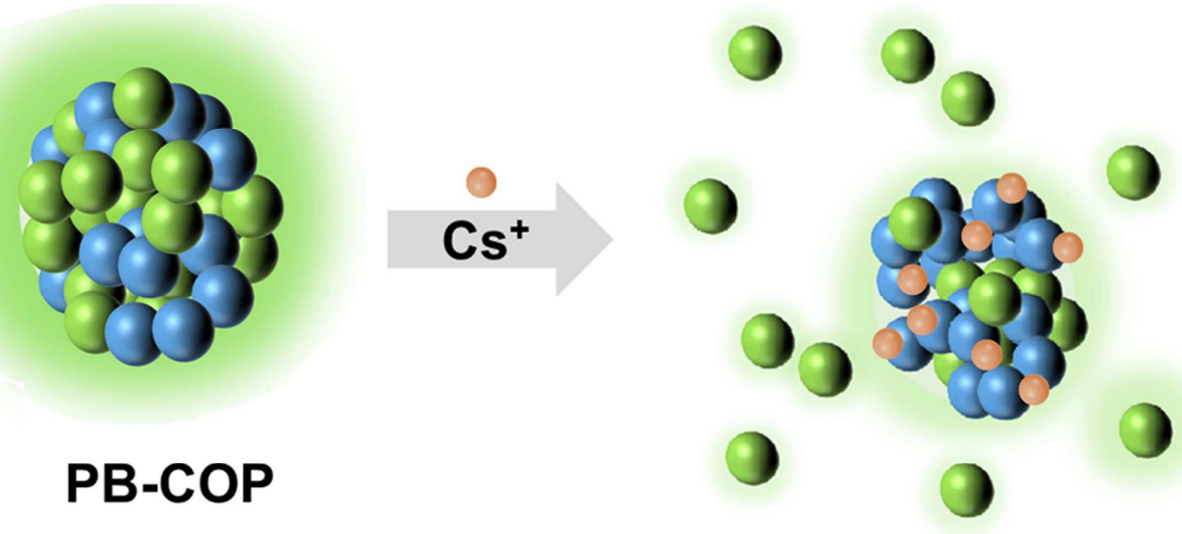

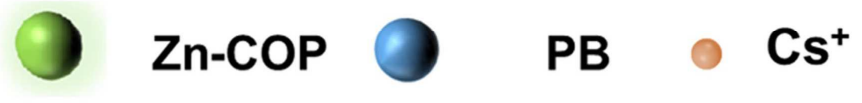

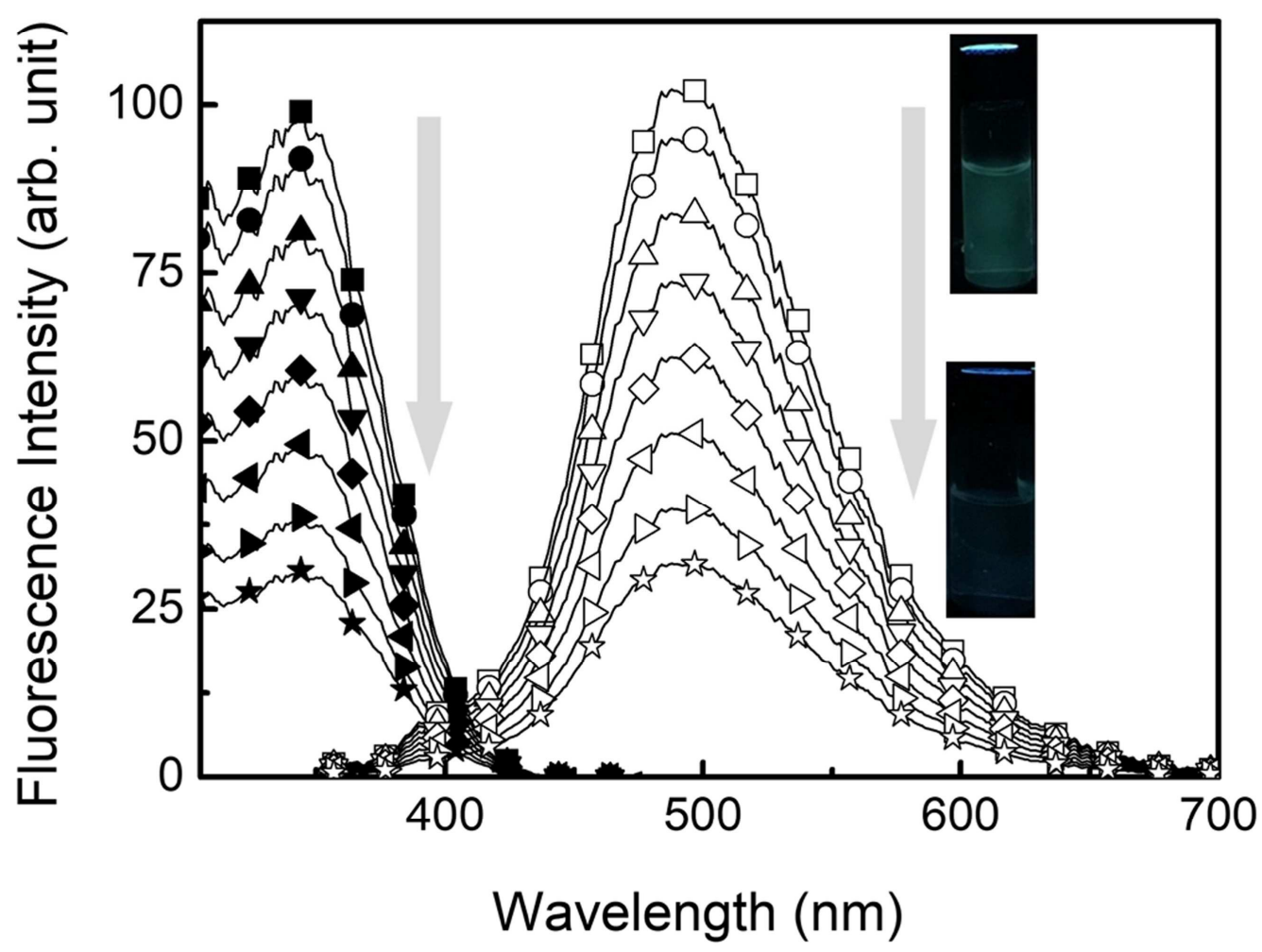


Synthesis of Prussian blue-embedded porous polymer for detection and removal of Cs ions

Ho Namgung, ,a Young Jin Gwon,a Jongho Kim, ${ }^{a}$ Geunseok Jang, a Sarah E. Pepper,

Mark D. Ogden, ${ }^{b}$ Karl R. Whittle, ${ }^{c}$ Laurence M. Harwood ${ }^{d}$ and Taek Seung Lee ${ }^{a, *}$

aOrganic and Optoelectronic Materials Laboratory, Department of Organic Materials Engineering, Chungnam National University, Daejeon 34134, Korea.

bDepartment of Chemical and Biological Engineering, University of Sheffield, Sheffield S1 3JD, United Kingdom.

‘School of Engineering, University of Liverpool, Liverpool L69 3BX, United Kingdom. dDepartment of Chemistry, University of Reading, Reading RG6 6AH, United Kingdom

* Corresponding author: Tel: +82-42-821-6615. E-mail: tslee@cnu.ac.kr 


\section{Abstract}

A Prussian blue (PB)-embedded coordination polymer (COP) was prepared by simple incorporation of PB into a COP composed of 1,1,2,2-tetrakis(4carboxyphenyl)ethane and the $\mathrm{Zn}$ ion during the synthesis of COP. The PB-COP was prepared as micro-sized particles with green emission $(490 \mathrm{~nm})$ from the strongly fluorescent tetraphenylethene group in the solid state through aggregation-induced emission. The PB-COP showed particle shape with sizes ranging from 1 to $6 \mu \mathrm{m}$. As the $\mathrm{PB}$ in PB-COP efficiently adsorbed Cs ions, the microstructure of PB-COP was degraded to smaller particles, along with a concomitant decrease in the green fluorescence of the PB-COP. Such a decrease in the green emission of PB-COP was used as a signal for the presence of Cs ions, in which the limit of detection for Cs ions was found to be $73.8 \mathrm{ppb}$. The hybridized material of the PB-COP can be used as both an efficient adsorbent and a sensor for Cs ions, achieving simultaneous removal and detection.

Keywords: fluorescent coordination polymer; Prussian blue; Cs ions 


\section{Introduction}

Metal-organic frameworks (MOFs) and coordination polymers (COPs) are new types of functional materials that attract much research interest [1-3]. COPs have a connection between organic linkers and inorganic nodes; therefore, they present peculiar supramolecular properties [4,5]. Among their intriguing properties and resulting versatile applications, their unique flexibility renders them ideal candidates for stimuli-responsive materials [6]. Moreover, various functional materials such as polymers [7], carbon nanotubes [8], metal nanoparticles [9], and biomolecules have been integrated to obtain hybrid materials in which COPs and MOFs have been used as platforms. Because of their synergistic properties, the hybrid or composite materials demonstrate a more effective performance than the corresponding MOFs or COPs alone. COPs and functional species can be combined by using the interaction between them, which will be an efficient methodology for a robust support material. This will prevent possible leaks of small colloidal species such as Prussian blue (PB) [10].

PB is composed of Fe ion nodes linked with a cyanide-based framework that shows absorption of red and near-infrared lights, providing a characteristic blue color induced by the charge transfer between the metal cations. PB has been also prepared by using various metal cations including Co (II) and Zn (II), instead of Fe (III) [11-13], and exhibited a wide variety of potential applications such as photothermal therapy and ultrasound imaging [14]. Moreover, PB, composed of 
ferric hexacyanoferrate, is known for its powerful ability to adsorb Cs ions [15-17]. However, PB is finely dispersible in aqueous phase; therefore it should be combined with supporting materials, such as sodium alginate [18,19], or fibrous [20], carbonaceous [21], magnetic materials [22,23], and silica [24,25], to form a composite material suitable for practical use. In relation to the accidents at nuclear power plants in Japan and Russia, large amounts of radioactive ${ }^{137} \mathrm{Cs}$, which is a product of nuclear fission, were released. Because of the danger of possible radiation leakage and exposure to harmful gamma rays from ${ }^{137} \mathrm{Cs}$, the removal of this radioisotope by $\mathrm{PB}$ has attracted much attention [26].

For PB to act as an efficient Cs-ion adsorbent, it should be hybridized with support materials such as the aforementioned COP. Such a COP would be promising if it is fluorescent and could detect the presence of Cs ions via alteration of its fluorescence signal. This would result in the simultaneous detection and removal of Cs ions. Meanwhile, materials with such dual functions are very rare. The fluorescence of most conventional fluorescent molecules tends to decrease in their solid state compared to their solutions because of the aggregation-caused quenching effect. By contrast, organic fluorophores that are nonfluorescent in solution, but are highly emissive in their solid state, have been reported to exhibit the aggregationinduced emission (AIE) effect $[27,28]$. It can be expected that the introduction of the AIE function to the rigid COP matrix can provide more efficient fluorescent-sensing properties. Among the AIE fluorophores, 1,1,2,2-tetrakis(4-carboxy)ethene (TPE) and 
its analogues can be used as building blocks to synthesize a COP, in which the enhanced emission TPE [29] is used for chemical sensors [30], white light-emitting diodes [31], and mechanochromic fluorophores [7]. Similarly, TPE derivatives have been used as a building block for MOF, via the functionalization of TPE with coordination groups, including pyridine and carboxylic acid groups [30,32-35]. The TPE-based MOFs can be used as effective sensors for volatile organic compounds and nitro-based explosives [36-38], based on the mechanism of photo-induced energy transfer (PET) between TPE and targets [39-41].

We designed the hybridization of the Cs-adsorbing PB and fluorescent COP for both fluorescent sensing and removal of Cs ions. We used TPE as a fluorescent component for the synthesis of COP via the polymerization of $\mathrm{Zn}$ ions and TPEcontaining tetracarboxylic acid. The hybridization of PB and COP (PB-COP) was carried out simply by the polymerization of COP in the presence of PB. Upon exposure of the $\mathrm{PB}-\mathrm{COP}$ to $\mathrm{Cs}$ ions, the structure of the micro-sized PB-COP collapsed because of Cs adsorption on PB. Simultaneously, the green emission of PBCOP became quenched because of the release of the TPE from the COP into the medium used, resulting in PET. We demonstrated the performance of PB-COP in fluorescent detection and removal of Cs ions by changes in both fluorescence and shape.

\section{Experimental}




\subsection{Materials and instrumentation}

All chemicals were purchased from Sigma-Aldrich (USA) and the solvents were purchased from Samchun Chemicals (Korea). All the reagents were used without further purification unless otherwise noted. PB was prepared according to the method described previously in the literature [11]. Tetraphenylethylene (1), 1,1,2,2tetrakis(4-bromophenyl)ethene (2), 1,1,2,2-tetrakis(4-cyanophenyl)-ethene (3), and 1,1,2,2-tetrakis(4-carboxyphenyl)ethene (4) were synthesized according to previous methods [29,42]. ${ }^{1} \mathrm{H}$ NMR spectra were obtained using a Bruker DRX-300 spectrometer (Korea Basic Science Institute). FT-IR spectra were recorded on a Tensor 27 FT-IR spectrometer (Bruker). UV-vis absorption spectra were recorded on a PerkinElmer Lambda 35 spectrometer. Photoluminescence spectra were taken using a Varian Cary Eclipse spectrophotometer equipped with a Xe-lamp excitation source. Zeta-potentials and size of particles were measured using dynamic light scattering (DLS; Zetasizer Nano ZS; Malvern). Scanning electron microscopic (SEM) images were obtained with a Hitachi S-4800 instrument. Transmission electron microscopic (TEM) images and energy-dispersive X-ray spectroscopy (EDS) data were taken using a JEM-3011, JEOL TEM instrument. The concentration of Cs ions in aqueous solution was determined by an inductively coupled plasma atomic emission spectrometer (ICP-AES, OPTIMA 7300 DV).

\subsection{Synthesis of the COP}


$4(0.03 \mathrm{~g}, 0.06 \mathrm{mmol})$ was dissolved in ethanol $(3 \mathrm{~mL})$ and zinc nitrate $(0.15 \mathrm{~g}, 0.57$ $\mathrm{mmol})$ was dissolved in separate ethanol $(3 \mathrm{~mL})$. The ethanol solutions of $4(0.5 \mathrm{~mL})$ and zinc nitrate $(0.5 \mathrm{~mL})$ were mixed with ethanol $(5 \mathrm{~mL})$. The mixture was heated to $80{ }^{\circ} \mathrm{C}$ for $24 \mathrm{~h}$. After cooling to room temperature, the mixture was isolated by centrifugation at $12000 \mathrm{rpm}$ for $15 \mathrm{~min}$ and washed with ethanol for three times. FTIR (KBr pellet, $\left.\mathrm{cm}^{-1}\right): 3398(\mathrm{O}-\mathrm{H}), 1600(\mathrm{C}=\mathrm{O})$, 1541-1408 (C=C). EA Found. C, 39.4\%; H, 2.0\%; N, 5.9\%.

\subsection{Synthesis of PB- COP}

$4(0.03 \mathrm{~g}, 0.06 \mathrm{mmol})$ was dissolved in ethanol $(3 \mathrm{~mL})$ and zinc nitrate $(0.15 \mathrm{~g}, 0.57$ mmol) was separately dissolved in ethanol $(3 \mathrm{~mL})$. The ethanol solution of PB $(1 \mathrm{~mL}$, $0.03 \mathrm{mg} / \mathrm{mL}$ ) was added to N,N-dimethylformamide (DMF; $14 \mathrm{~mL}$ ) under sonication. The ethanol solution of $4(0.5 \mathrm{~mL})$ and the zinc solution $(0.5 \mathrm{~mL})$ were added to the mixture. The mixture was heated to $80{ }^{\circ} \mathrm{C}$ for $24 \mathrm{~h}$. After cooling to room temperature, the mixture was isolated by centrifugation at $12000 \mathrm{rpm}$ for $15 \mathrm{~min}$ and washed with ethanol three times. FT-IR (KBr pellet, $\left.\mathrm{cm}^{-1}\right)$ : 3411-3388 (O-H), 2092 $(\mathrm{C} \equiv N), 1658(\mathrm{C}=\mathrm{O}), 1602(\mathrm{C}=\mathrm{O}), 1541-1408(\mathrm{C}=\mathrm{C})$. EA Found. $\mathrm{C}, 42.9 \% ; \mathrm{H}, 3.1 \%$; $11.7 \%$. 


\subsection{Detection of Cs ions using PB-COP}

PB-COP was suspended in ethanol $(0.025 \mathrm{mg} / \mathrm{mL})$ and exposed to Cs ions. The changes in the fluorescence of PB-COP were investigated. The changes in the shape of PB-COP before and after exposure to Cs ions were investigated using SEM and TEM.

\subsection{Adsorption of Cs ions}

The Cs-ion adsorption behavior of $\mathrm{PB}$ and $\mathrm{PB}-\mathrm{COP}$ was investigated at ambient temperature. Upon exposure of the PB $(0.3 \mathrm{mg} / \mathrm{mL})$ and PB-COP $(0.25 \mathrm{mg} / \mathrm{mL})$ to Cs ions (50 ppm), the adsorption behavior was monitored up to $48 \mathrm{~h}$. After separating the adsorbents from their solutions by centrifugation, the concentration of adsorbed Cs ions was determined by ICP-AES. The adsorption capacity $\left(\mathrm{q}_{\mathrm{t}}\right)$ was determined using the following equation:

$\boldsymbol{q}_{t}=\frac{\left(\mathrm{C}_{0}-\mathrm{C}_{t}\right) \times \mathrm{V}}{M}$

Where $C_{0}$ and $C_{t}$ are the initial $C s$ concentration and the Cs concentration after adsorption time $(\mathrm{t})$, respectively, $\mathrm{V}$ is the solution volume $(3 \mathrm{~mL})$, and $\mathrm{M}$ is the weight of the adsorbent used. 


\section{Results and discussion}

\subsection{Synthesis and characterization of COP}

TPE with the tetracarboxylic acid groups (4) was synthesized from 3 and the synthetic route to 4 is illustrated in Scheme 1. 1, 2, 3, and 4 were synthesized according to previous literature and the chemical structures were confirmed by ${ }^{1} \mathrm{H}$ NMR. The TPE-based compounds were soluble in chloroform and tetrahydrofuran (THF) and exhibited strong emissions in the solid state because of AIE. The UV-vis spectra of 1, 2, and 4 solid films with good quality showed absorptions at 322, 330, and $345 \mathrm{~nm}$, respectively (Fig. S1a). Strong fluorescence emissions were observed at 450, 480, and $500 \mathrm{~nm}$ for compounds 1, 2, and 4, respectively (Fig. S1b). Photographs of the spin-cast films of 1, 2, and 4 under ambient and UV light $(365 \mathrm{~nm})$ showed that the blue emission of 1 shifted gradually to green (4) via greenish blue (2), depending on the substituents attached on TPE, presumably because of the difference in the electron-withdrawing effect.

The coordination polymer COP was prepared via reaction between the carboxylic acid groups of 4 and $\mathrm{Zn}$ ions in ethanol (Scheme 1). COP showed uniform and stable dispersion in ethanol for one month. The FT-IR spectrum of COP showed the characteristic bands of $\mathrm{C}=\mathrm{O}, \mathrm{C}=\mathrm{C}$, and $\mathrm{O}-\mathrm{H}$ bands, indicating that the $\mathrm{COP}$ was resulted from 4 (Fig. S2). The excitation and fluorescence spectra of COP were investigated, exhibiting a green emission band around $490 \mathrm{~nm}$ with an excitation wavelength of $345 \mathrm{~nm}$ (Fig. 1a). Although the emission of COP was slightly blue- 
shifted compared with that of $\mathbf{4}$, the green fluorescence from TPE via AIE was still maintained as shown in the photographs of the COP dispersion under UV light (inset of Fig. 1a). The SEM image indicates that the COP had a particulate-shape with an average size of $60 \mathrm{~nm}$ (Fig. 1b).

\subsection{Synthesis and optical properties of PB}

The absorption spectrum of $\mathrm{PB}$ presents a broad absorption at $700 \mathrm{~nm}$, exhibiting blue color (Fig. S3a). The particle size of PB was determined to be about $50 \mathrm{~nm}$, as determined by SEM (Fig. S3b). Upon exposure of the PB to Cs ion (50 ppm), the absorption of PB decreased with increasing exposure time (Fig. 2a), indicating that the charge transfer between Fe (III) and Fe (II) ions on PB, which the blue color of PB, has changed in the presence of Cs ions. As the concentration of Cs ions increased from 6.25 to $50 \mathrm{ppm}$, the absorption of PB gradually decreased with a slight blueshift to $673 \mathrm{~nm}$ (Fig. 2b). The absorption remained unchanged when the concentration of Cs ions was above 20 ppm (Fig. 2c). The change in the PB shape was confirmed in an SEM image, in which the decrease in the UV-vis absorption might result from the aggregation following the partial destruction of the PB structure after adsorption of Cs ions (Fig. 2d). Although the adsorption mechanism of Cs ions by PB has not been elucidated yet, an ion-exchange mechanism is generally accepted, in a way that Cs ions with a smaller radius ( $1.19 \AA$ ) fitted in the PB lattice space instead of $\mathrm{K}(1.25 \AA)$ or Na ions $(1.84 \AA)$, leading to the replacement of a $\mathrm{K}$ ion by a Cs ion 
$[21,43,44]$. Thus, the crystal structure of PB was altered by the ion-exchange with Cs ions, resulting in changes in both the UV-vis absorption and the shape of PB. The amount of Cs ions adsorbed by PB was determined with ICP (Table 1). After exposure of $48 \mathrm{~h}$ to Cs ions (50 ppm), more than $60 \%$ of Cs ion was removed by the PB.

\subsection{Synthesis and optical properties of PB-COP}

PB-COP (COP hybridized with PB) was obtained when the COP was prepared in the presence of PB (Scheme 2). The PB was successfully incorporated to COP, in which the characteristic band of nitrile group was shown in FT-IR spectrum (Fig. S2). Because Fe ions in PB can bind to the carboxylic acid group of 4, this, in turn, might help PB-embedding inside the COP. PB-COPs were particle-shaped with a size ranging from 1 to $6 \mu \mathrm{m}$ and exhibited stable dispersion in ethanol. For the preparation of an optimal adsorbent for Cs ions, various amounts of COP and PB were used and their particle size is illustrated (Table S1). A spherical shape with rough surface was observed for PB-COPs, regardless of their different compositions (Table 2). The excitation and fluorescence spectra of PB-COP1 exhibited maximum excitation at $345 \mathrm{~nm}$ and emission at $490 \mathrm{~nm}$, respectively (Fig. 3a). The EDS images indicate that $\mathrm{Fe}$ atoms from $\mathrm{PB}$ were located in the same region in which the $\mathrm{Zn}$ atoms were present in COP (Fig. S4a). Because of the efficient embedding of PB to obtain fluorescent PB-COP1, this combination was used to detect Cs ions. 


\subsection{Detection of Cs ions}

To elucidate the change in PB-COP1 fluorescence upon exposure to Cs ions, an aqueous solution of cesium chloride (50 ppm) was added to PB-COP1 $(0.025 \mathrm{mg} / \mathrm{mL}$ in ethanol) and the changes in PB-COP1 fluorescence were recorded after $48 \mathrm{~h}$. The fluorescence of PB-COP1 decreased with increasing concentration of Cs ions (Fig. 3). The fluorescence of PB-COP1 decreased with increasing concentration of Cs ions in a linear relationship, in which the fluorescence quenching of PB-COP1 was also observed by the naked-eye. The quenching efficiency $\left(\mathrm{F}_{0} / \mathrm{F}\right)$ in the presence of $\mathrm{Cs}$ ions was quantified using the Stern-Volmer equation:

$$
\mathrm{F}_{0} / \mathrm{F}=1+\mathrm{K}_{\mathrm{sv}}[\mathrm{Q}]
$$

where $\mathrm{F}_{0}$ and $\mathrm{F}$ are the fluorescence intensity at $490 \mathrm{~nm}$ before and after exposure to Cs ions, respectively, $K_{\mathrm{sv}}$ is a Stern-Volmer quenching constant, and [Q] is the concentration of the quencher. The limit of detection was calculated to be $73.8 \mathrm{ppb}$, based on the $3 \sigma /$ slope, where $\sigma$ is the standard deviation of four independent measurements. The adsorption of Cs ions by the insoluble PB resulted mainly from the ion-exchange between $\mathrm{Cs}$ ions and/or the monovalent cations ( $\mathrm{K}$ ions) in the $\mathrm{PB}$ lattice, because the hydrated Cs ions fit the cage size of PB lattice $[19,26]$. The PB adsorbed $\mathrm{Cs}$ ions and $\mathrm{K}$ ions in the PB lattice was replaced by the Cs ions via ion exchange, leading to deformation of the PB structure because of size difference, and finally to disruption of the PB-COP. During such an event, the fluorescence of PB- 
COP was quenched via PET.

Along with the fluorescence changes upon exposure to Cs ions, the sphericallyshaped PB-COP1 particles were considerably deformed; the micro-sized PB-COP1 particles became degraded into smaller nanoparticles with an average size of $50 \mathrm{~nm}$ and, finally aggregated. The structural disruption of PB-COP1 and aggregation were confirmed by SEM (Fig. 4) and EDS mapping (Fig. S3b). According to the EDS images, after Cs exposure to PB-COP1, Zn atoms were more distributed outside the framework compared with the distribution of Fe atoms, indicative of an easier destruction of the COP structure than that of PB by the adsorption of Cs ions. After exposure of PB-COP1 to Cs ions, the $\mathrm{K}$ ions in the PB structure were replaced by the former, leading to weakening of the interaction between PB and COP. The resulting destruction of the PB-COP structure facilitated the separation of COP from PB-COP (Scheme 2). The separated and degraded COP became less fluorescent because the TPE units became miscible in the medium (ethanol). This resulted in the fact that the AIE could not work anymore and PET-induced quenching occurred.

\subsection{Adsorption of Cs ions}

To verify the adsorption efficiency of PB-COP1 toward Cs ions, 50 ppm Cs ions were exposed to PB-COP1 dispersion and the amount of Cs ions adsorbed was determined with ICP. After $48 \mathrm{~h}$ exposure, the dispersion was subjected to centrifugation at $12000 \mathrm{rpm}$ to separate PB-COP1 from the solution, and the amount 
of Cs ions remaining in the supernatant was observed by ICP (Table 1). $30.7 \mathrm{ppm}$ of Cs ions remained in the solution and 19.3 ppm was adsorbed by PB-COP1. 61\% of Cs ions were captured by the hybrid adsorbent PB-COP1. It seems slightly low, compared with the $67 \%$ Cs ions removed by PB. However, considering the amount of $\mathrm{PB}$ embedded in PB-COP1, the hybrid adsorbent was more efficient than simple $\mathrm{PB}$, presumably due to uniform distribution in COP. A relatively lower PB content is needed in the hybrid material, which renders this approach more promising in the preparation of a PB-based adsorbent. According to the adsorption capacity $\left(q_{t}\right)$ of PB$\mathrm{COP} 1$ and $\mathrm{PB}$ for Cs ions, adsorption equilibrium was attained in less than $10 \mathrm{~h}$ in both cases (Fig. 5). Regarding the adsorption kinetics, chemisorption was preferred because the curve fitting was more suitable for the pseudo second-order kinetic model (Fig S5). This indicates that the PB within the PB-COP1 acts as an efficient adsorbent for Cs ions even at the lower amount. Based on these results, PB-COP could detect Cs ions via fluorescence change and also capture them, exhibiting a versatile use of the hybrid material.

\section{Conclusion}

A hybrid material of a fluorescent TPE-based COP and Cs-adsorbing PB was prepared in the presence of $\mathrm{Zn}$ nodes. The micro-sized spherical PB-COPs (1 to $6 \mu \mathrm{m}$ ) exhibited green emission $(490 \mathrm{~nm})$ because of the presence of TPE units in the COP. Upon exposure of the PB-COP to Cs ions, the Cs ions were efficiently adsorbed by 
the PB-COP (67\% removal from 50 ppm Cs ions). Simultaneously, the micro-sized particles of PB-COP were destroyed to form smaller particles with a hollow structure, and subsequently, the fluorescence of PB-COP decreased because the COP building block was destroyed to liberate TPE into the medium, inducing PET. The limit of detection for Cs ions were found to be $73.8 \mathrm{ppb}$. Thus, PB-COP could detect Cs ions, as indicated by changes in the fluorescence. In addition, Cs ions could be removed through the specific adsorption.

\section{Acknowledgment}

Financial support from the National Research Foundation of Korea (NRF) funded by Korean government through the Nuclear R\&D Projects (2015M2A7A1000217, 2016M2B2B1945085) is gratefully acknowledged.

\section{References}

[1] N.R. Catarineu, A. Schoedel, P. Urban, M.B. Morla, C.A. Trickett, O.M. Yaghi, Two principles of reticular chemistry uncovered in a metal-organic framework of heterotritopic linkers and infinite secondary building units, J. Am. Chem. Soc. 138 (2016) 10826-10829.

[2] B. Li, H.-M. Wen, Y. Cui, W. Zhou, G. Qian, B. Chen, Emerging multifunctional metal-organic framework materials, Adv. Mater. 28 (2016) 8819-8860. 
[3] T.R. Cook, Y.R. Zheng, P.J. Stang, Metal-organic frameworks and selfassembled supramolecular coordination complexes: comparing and contrasting the design, synthesis, and functionality of metal-organic materials, Chem. Rev. 113 (2013) 734-777.

[4] J.P. Zhang, X.-C. Huang, X.-M. Chen, Supramolecular isomerism in coordination polymers, Chem. Soc. Rev. 38 (2009) 2385-2396.

[5] S.-S. Zhao, L. Chen, X. Zheng, L. Wang, Z. Xie, PEG-induced synthesis of coordination-polymer isomers with tunable architectures and iodine capture, Chem.-Asian J. 12 (2017) 615-620.

[6] A. Schneemann, V. Bon, I. Schwedler, I. Senkovska, S. Kaskel, R.A. Fischer, Flexible metal-organic frameworks, Chem. Soc. Rev. 43 (2014) 6062-6096.

[7] S.S. Zhao, L. Chen, L. Wang, Z. Xie, Two tetraphenylethene-containing coordination polymers for reversible mechanochromism, Chem. Commun. 53 (2017) 7048-7051.

[8] Q.L. Zhu, Q. Xu, Metal-organic framework composites, Chem. Soc. Rev. 43 (2014) 5468-5512.

[9] G. Lu, S. Li, Z. Guo, O.K. Farha, B.G. Hauser, X. Qi, Y. Wang, X. Wang, S. Han, X. Liu, J.S. DuChene, H. Zhang, Q. Zhang, X. Chen, J. Ma, S.C.J. Loo, W.D. Wei, Y. Yang, J.T. Hupp, F. Huo, Imparting functionality to a metal-organic framework material by controlled nanoparticle encapsulation, Nat. Chem. 4 (2012) 310-316. 
[10] J. Guan, Y. Hu, Y. Wang, H. Li, Z. Xu, T. Zhang, P. Wu, S. Zhang, G. Xiao, W. Ji, L. Li, M. Zhang, Y. Fan, L. Li, B. Zheng, W. Zhang, W. Huang, F. Huo, Controlled encapsulation of functional organic molecules within metal-organic frameworks: in situ crystalline structure transformation, Adv. Mater. 29 (2017) 1606290.

[11] W. Zhu, K. Liu, X. Sun, X. Wang, Y. Li, L. Cheng, Z. Liu, Mn²+-doped Prussian blue nanocubes for bimodal imaging and photothermal therapy with enhanced performance, ACS Appl. Mater. Interfaces 7 (2015) 11575-11582.

[12] M. Hu, S. Furukawa, R. Ohtani, H. Sukegawa, Y. Nemoto, J. Reboul, S. Kitagawa, Y. Yamauchi, Synthesis of Prussian blue nanoparticles with a hollow interior by controlled chemical etching, Angew. Chem. Int. Ed. 51 (2012) 984988.

[13] J. Balmaseda, E. Reguera, J. Fernandez, A. Gordillo, H. Yee-Madeira, Behavior of Prussian blue-based materials in presence of ammonia, J. Phys. Chem. Solids 64 (2003) 685-693.

[14] X. Jia, X. Cai, Y. Chen, S. Wang, H. Xu, K. Zhang, M. Ma, H. Wu, J. Shi, H. Chen, Perfluoropentane-encapsulated hollow mesoporous Prussian blue nanocubes for activated ultrasound imaging and photothermal therapy of cancer, ACS Appl. Mater. Interfaces 7 (2015) 4579-4588.

[15] J.C. Wojdel, S.T. Bromley, Band gap variation in Prussian blue via cationinduced structural distortion, J. Phys. Chem. B 110 (2006) 24294-24298. 
[16] B. Hu, B. Fugetsu, H. Yu, Y. Abe, Prussian blue caged in spongiform adsorbents using diatomite and carbon nanotubes for elimination of cesium, J. Hazard. Mater. 217 (2012) 85-91.

[17] W.E. Prout, E.R. Russell, H.J. Groh, Ion exchange absorption of cesium by potassium hexacyanocobalt (II) ferrate (II), J. Inorg. Nucl. Chem. 27 (1965) 473479.

[18] A. Tokarev, P. Agulhon, J. Long, F. Quignard, M. Robitzer, R.A. Ferreira, L.D. Carlos, J. Larionova, C. Guérin, Y. Guari, Synthesis and study of Prussian blue type nanoparticles in an alginate matrix, J. Mater. Chem. 22 (2012) 20232-20242.

[19] K. Vipin, B. Hu,B. Fugetsu, Prussian blue caged in alginate/calcium beads as adsorbents for removal of cesium ions from contaminated water, J. Hazard. Mater. 258 (2013) 93-101.

[20] Y. Okamura, K. Fujiwara, R. Ishihara, T. Sugo, T. Kojima, D. Umeno, K. Saito, Cesium removal in freshwater using potassium cobalt hexacyanoferrateimpregnated fibers, Rad. Phys. Chem. 94 (2014) 119-122.

[21] S.-C. Jang, Y. Haldorai, G.-W. Lee, S.-K. Hwang, Y.-K. Han, C. Roh, Y.S. Huh, Porous three-dimensional graphene foam/ Prussian blue composite for efficient removal of radioactive 137Cs, Sci. Rep. 5 (2015) 17510.

[22] H.-M. Yang, S.-C. Jang, S.B. Hong, K.-W. Lee, C. Roh, Y.S. Huh, B.-K. Seo, Prussian blue-functionalized magnetic nanoclusters for the removal of radioactive cesium from water, J. Alloys Compounds 657 (2016) 387-393. 
[23] H. Yang, L. Sun, J. Zhai, H. Li, Y. Zhao, H. Yu, In situ controllable synthesis of magnetic Prussian blue/graphene oxide nanocomposites for removal of radioactive cesium in water, J. Mater. Chem. A 2 (2014) 326-332.

[24] R. Turgis, G. Arrachart, C. Delchet, C. Rey, Y. Barre, S. Pellet-Rostaing, Y. Guari, J. Larionova, A. Grandijean, An original "click and bind" approach for immobilizing copper hexacyanoferrate nanoparticles on mesoporous silica, Chem. Mater. 25 (2013) 4447-4453.

[25] M.R. Awual, Y. Miyazaki, T. Taguchi, H. Shiwaku, T. Yaita, Encapsulation of cesium from contaminated water with highly selective facial organic-inorganic mesoporous hybrid adsorbent, Chem. Eng. J. 291 (2016) 128-137.

[26] X. Liu, G.-R. Chen, D.-J. Lee, T. Kawamoto, H. Tanaka, M.-L. Chen, Y.-K. Luo, Adsorption removal of cesium from drinking waters: A mini review on use of biosorbents and other adsorbents, Bioresource technology 160 (2014) 142-149.

[27] Y.N. Hong, J.W.Y. Lam, B.Z. Yang, Aggregation-induced emission, Chem. Soc. Rev. 40 (2011) 5361-5388.

[28] S. Zhang, A. Qin, J.Z. Sun, B.Z. Tang, Progress in mechanism study of aggregation-induced emission (in Chinese), Prog. Chem. 23 (2011) 623-636.

[29] N.B. Shustova, T.-C. Ong, A.F. Cozzolino, V.K. Michaelis, R.G. Griffin, M. Dincă, Phenyl ring dynamics in a tetraphenylethylene-bridged metal-organic framework: implications for the mechanism of aggregation-induced emission, J. Am. Chem. Soc. 134 (2012) 15061-15070. 
[30] M. Zhang, G. Feng, Z. Song, Y. Zhou, H. Chao, D. Yuan, T.T.Y. Tan, Z. Guo, Z. Hu, B. Tang, B. Liu, D. Zhao, Two-dimensional metal-organic framework with wide channels and responsive turn-on fluorescence for the chemical sensing of volatile organic compounds, J. Am. Chem. Soc. 136 (2014) 7241-7244.

[31] Q. Gong, Z. Hu, B.J. Deibert, T.J. Emge, S.J. Teat, D. Banerjee, B. Mussman, N.D. Rudd, J. Li, Solution processable MOF yellow phosphor with exceptionally high quantum efficiency, J. Am. Chem. Soc. 136 (2014) 16724-16727.

[32] Y. Cui, B. Li, H. He, W. Zhou, B. Chen, G. Qian, Metal-organic frameworks as platforms for functional materials, Acc. Chem. Res. 49 (2016) 483-493.

[33] Z. Zhou, C. He, J. Xiu, L. Yang, C. Duan, Metal-organic polymers containing discrete single-walled nanotube as a heterogeneous catalyst for the cycloaddition of carbon dioxide to epoxides, J. Am. Chem. Soc. 137 (2015) 15066-15069.

[34] A. Douvali, A.C. Tsipis, S.V. Eliseeva, S. Petoud, G.S. Papaefstathiou, C.D. Malliakas, I. Papadas, G.S. Armatas, I. Margiolaki, M.G. Kanatzidis, T. Lazarides, M.J. Manos, Turn-on luminescence sensing and real-time detection of traces of water in organic solvents by a flexible metal-organic framework, Angew. Chem., Int. Ed. 54 (2015) 1651-1656.

[35] X.-G. Liu, H. Wang, B. Chen, Y. Zou, Z.-G. Gu, Z. Zhao, L. Shen, A luminescent metal-organic framework constructed using a tetraphenylethene-based ligand for sensing volatile organic compounds, Chem. Commun. 51 (2015) 1677-1680. 
[36] Y. Cui, Y. Yue, G. Qian, B. Chen, Luminescent functional metal-organic frameworks, Chem. Rev. 112 (2012) 1126-1162.

[37] X. He, V.W.-W. Yam, Luminescent gold(I) complexes for chemosensing, Coord. Chem. Rev. 255 (2011) 2111-2123.

[38] Z. Hu, B.J. Deibert, J. Li, Luminescent metal-organic frameworks for chemical sensing and explosive detection, Chem. Soc. Rev. 43 (2014) 5815-5840.

[39] M.D. Allendorf, C.A. Bauer, R.K. Bhakta, R.J.T. Houk, Luminescent metalorganic frameworks, Chem. Soc. Rev. 38 (2009) 1330-1352.

[40] L.-Y. Guo, H.-F. Su, M. Kurmoo, X.-P. Wang, Q.-Q. Zhao, S.-C. Lin, C.-H. Tung, D. Sun, L.-S. Zheng, Multifunctional triple-decker inverse 12-metallacrown-4 sandwiching halides, ACS Appl. Mater. Interfaces 9 (2017) 19980-19987.

[41] S. Jo, J. Kim, J. Noh, D. Kim, G. Jang, N. Lee, E. Lee, T.S. Lee, Conjugated polymer dots-on-electrospun fibers as a fluorescent nanofibrous sensor for nerve gas stimulant, ACS Appl. Mater. Interfaces, 6 (2014) 22884-22893.

[42] N.B. Shustova, B.D. McCarthy, M. Dinca, Turn-on fluorescence in tetraphenylethylene-based metal-organic frameworks: an alternative to aggregation-induced emission, J. Am. Chem. Soc. 133 (2011) 20126-20129.

[43] P.C.F. Pau, J. Berg, W. McMillan, Application of Stokes' law to ions in aqueous solution, J. Phys. Chem. 94 (1990) 2671-2679.

[44] A.K. Vipin, B. Fugetsu, I. Sakata, A. Isogai, M. Endo, M. Li, M. S. Dresselhaus, Cellulose nanofiber backboned Prussian blue nanoparticles as powerful 
adsorbents for the selective elimination of radioactive cesium, Sci. Rep. 6 (2016) 37009. 


\section{Figure Captions and Table Legends}

Scheme 1. Synthesis of COP.

Scheme 2. Synthesis of PB-COP (upper) and degradation of PB-COP in the presence of Cs ions (bottom).

Table 1. Adsorption of Cs Ions by PB and PB-COP1

Table 2. SEM images of PB-COPs.

Fig. 1. (a) Fluorescence (०) and excitation ( $\mathbf{-})$ spectra of COP in ethanol $(0.02 \mathrm{mg} / \mathrm{mL})$. Excitation wavelength: $345 \mathrm{~nm}$; Emission wavelength: $490 \mathrm{~nm}$. Inset photographs: COP in ethanol under visible and UV lights. (b) SEM image of COP.

Fig. 2. $(\mathrm{a}, \mathrm{b})$ Changes in absorption spectra of aqueous solution of $\mathrm{PB}(0.03 \mathrm{mg} / \mathrm{mL})$ upon exposure to $C s$ ion. (c) Relative absorption ratio $\left(A_{x} / A_{i}\right)$ of $P B$ after exposure to various concentrations of $\mathrm{Cs}_{\mathrm{s}}$ ion for $48 \mathrm{~h} . \mathrm{A}_{\mathrm{i}}$ and $\mathrm{A}_{\mathrm{x}}$ correspond to the absorbance at $696 \mathrm{~nm}$ before and after exposure to Cs ion, respectively. (d) SEM images of PB after exposure to Cs ion. White circle represents noticeable aggregation of COP fragments. $\left[\mathrm{Cs}^{+}\right]=50 \mathrm{ppm}$ for (a). Exposure time $48 \mathrm{~h}$ for $(\mathrm{b})$.

Fig. 3. (a) Changes in fluorescence (vacant) and excitation (filled) spectra of PB-COP1 $(\mathbf{\square}$, 口: $0.025 \mathrm{mg} / \mathrm{mL}$ in ethanol) upon exposure to Cs ion $(\bullet, \circ: 1 ; \mathbf{\Lambda}, \Delta: 5 ; \boldsymbol{\nabla}, \nabla: 10$; $\diamond, \diamond: 20 ; \triangleright, \triangleright: 30 ; \triangleleft, \triangleleft: 40 ; \star$, 㳊: $50 \mathrm{ppm}, 48 \mathrm{~h})$. Excitation wavelength: 345 
nm; Emission wavelength: $490 \mathrm{~nm}$; F0 and F are fluorescence intensities of PB-COP1 in the absence and presence of Cs ion at $490 \mathrm{~nm}$. (b) Stern-Volmer plot of fluorescence quenching of PB-COP1 in the presence of Cs ion. (c) Photographs of PBCOP1 dispersions under ambient and UV lights $(365 \mathrm{~nm})$ in the absence and presence of Cs ion (50 ppm).

Fig. 4. SEM images of PB-COP1 (a) before and (b) after addition of Cs ion (50 ppm, $48 \mathrm{~h})$.

Fig. 5. Effect of exposure time on the adsorption of Cs ion with (a) PB and (b) PBCOP1. 
$\stackrel{\mathrm{TiCl}_{4}, \mathrm{Zn}}{\longrightarrow}$<smiles>c1ccc(C(=C(c2ccccc2)c2ccccc2)c2ccccc2)cc1</smiles>

1

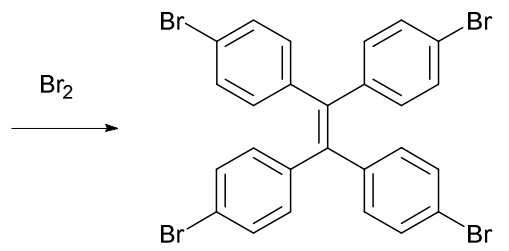

2<smiles>N#Cc1ccc(C(=C(c2ccc(C#N)cc2)c2ccc(C#N)cc2)c2ccc(C#N)cc2)cc1</smiles>

3

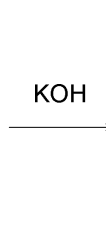<smiles>O=C(O)c1ccc(C(=C(c2ccc(C(=O)O)cc2)c2ccc(C(=O)O)cc2)c2ccc(C(=O)O)cc2)cc1</smiles>

4<smiles>[H][R10](=O)OC(=O)c1ccc(C(=C(c2ccc(C(=O)OCC)cc2)c2ccc(C(=O)OCC)cc2)c2ccc(C(=O)OCC)cc2)cc1</smiles>

COP

Scheme 1. Synthesis of COP. 
- $+4+\mathrm{Zn}\left(\mathrm{NO}_{3}\right)_{2} \longrightarrow$

\section{PB-COP}

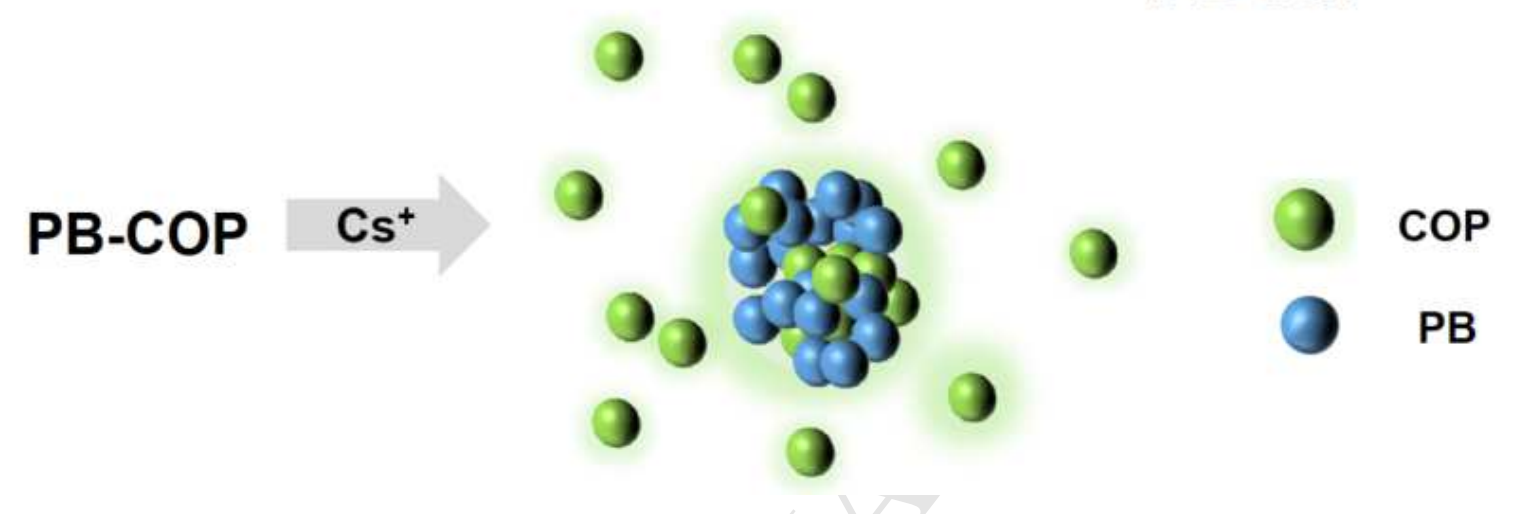

Scheme 2. Synthesis of PB-COP (upper) and degradation of PB-COP in the presence of Cs ions (bottom). 


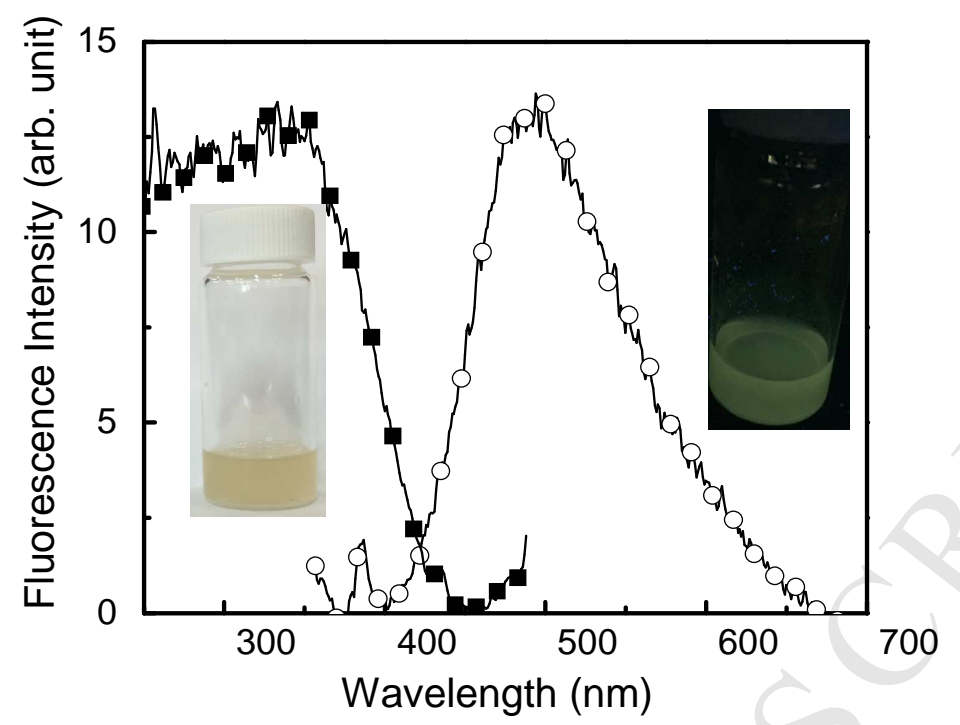

(a)

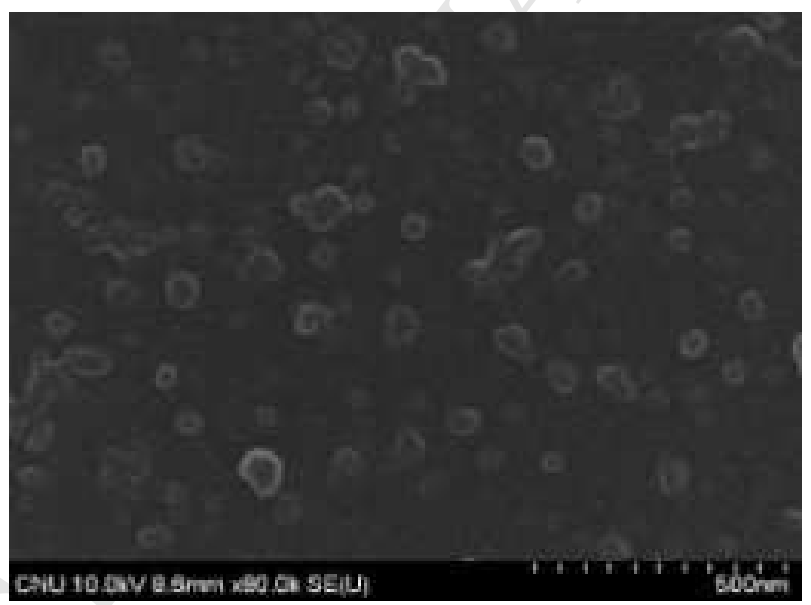

Fig. 1. (a) Fluorescence $(\bigcirc)$ and excitation $(\boldsymbol{\square})$ spectra of COP in ethanol $(0.02$ $\mathrm{mg} / \mathrm{mL}$ ). Excitation wavelength: $345 \mathrm{~nm}$; Emission wavelength: $490 \mathrm{~nm}$. Inset photographs: COP in ethanol under visible and UV lights. (b) SEM image of COP. 


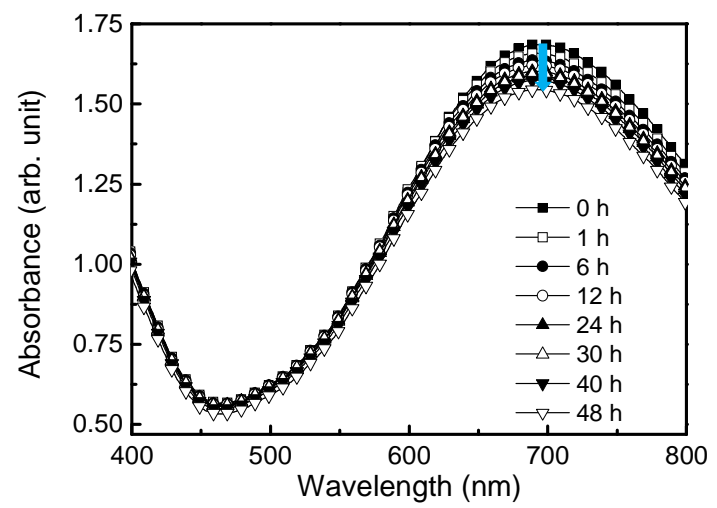

(a)

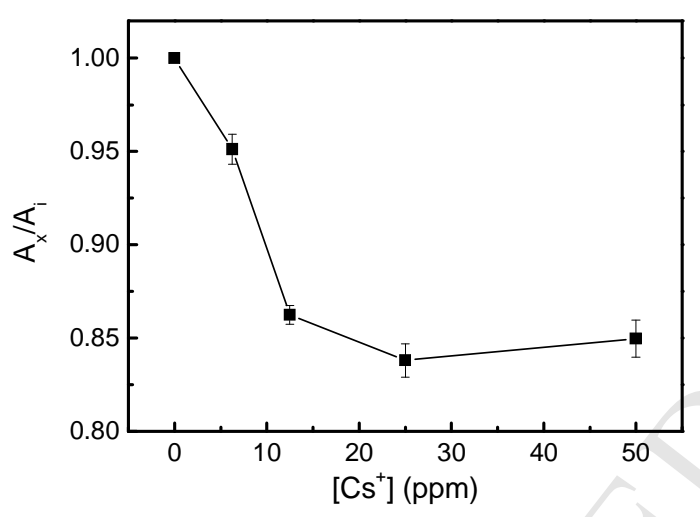

(c)

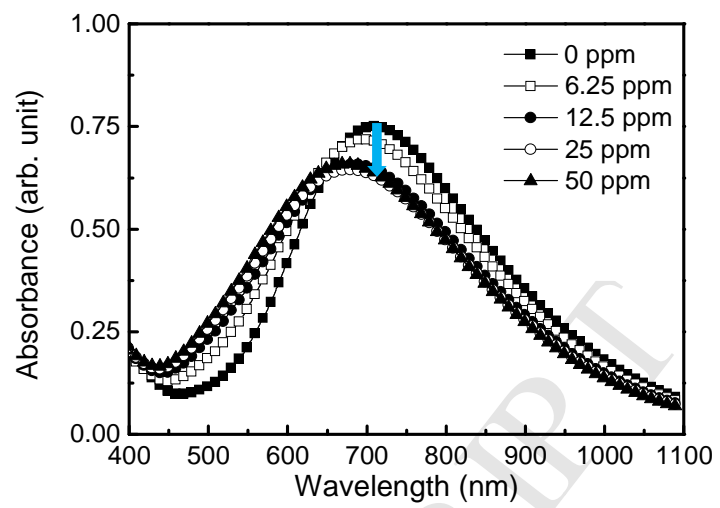

(b)

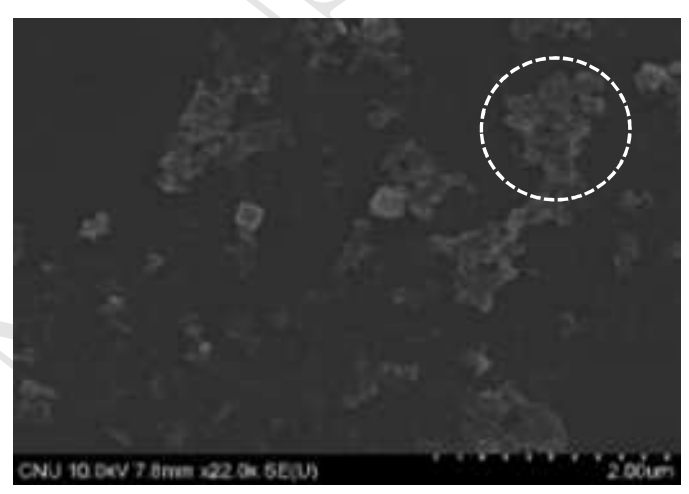

(d)

Fig. 2. $(a, b)$ Changes in absorption spectra of aqueous solution of PB $(0.03 \mathrm{mg} / \mathrm{mL})$ upon exposure to Cs ion. (c) Relative absorption ratio $\left(\mathrm{A}_{x} / \mathrm{A}_{\mathrm{i}}\right)$ of $\mathrm{PB}$ after exposure to various concentrations of Cs ion for $48 \mathrm{~h}$. $\mathrm{A}_{\mathrm{i}}$ and $\mathrm{A}_{\mathrm{x}}$ correspond to the absorbance at $696 \mathrm{~nm}$ before and after exposure to Cs ion, respectively. (d) SEM images of PB after exposure to Cs ion. White circle represents noticeable aggregation of COP fragments. $\left[\mathrm{Cs}^{+}\right]=50 \mathrm{ppm}$ for (a). Exposure time $48 \mathrm{~h}$ for $(\mathrm{b})$. 


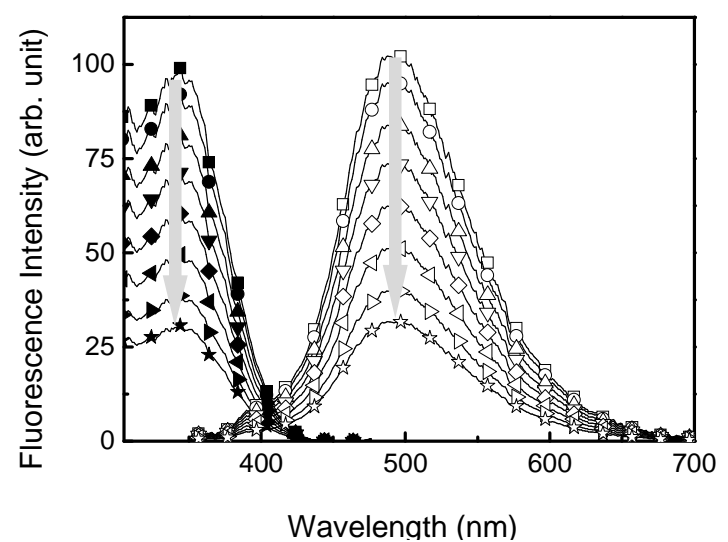

(a)

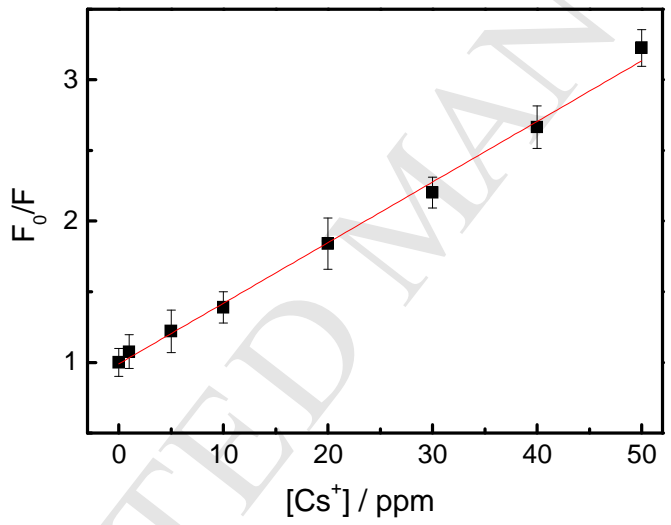

(b)

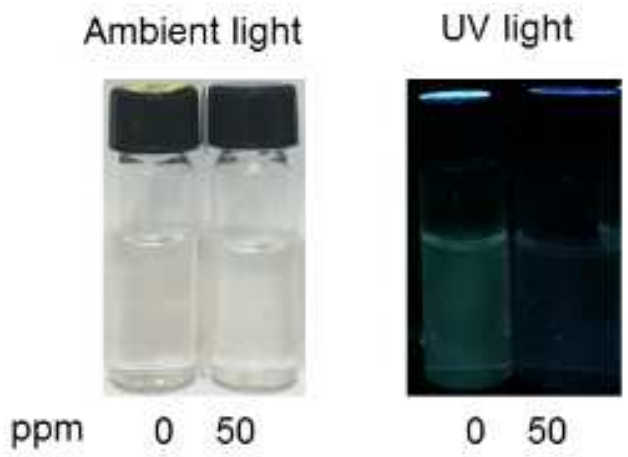

(c) 
Fig. 3. (a) Changes in fluorescence (vacant) and excitation (filled) spectra of PB-COP1 $(\boldsymbol{\bullet}$, 口: $0.025 \mathrm{mg} / \mathrm{mL}$ in ethanol) upon exposure to Cs ion $(\bullet, \circ: 1 ; \boldsymbol{\Lambda}, \Delta: 5 ; \boldsymbol{\nabla}, \nabla: 10$; $\diamond, \diamond: 20 ; \triangleright, \triangleright: 30 ; \triangleleft, \triangleleft: 40 ; \star$, 动: $50 \mathrm{ppm}, 48 \mathrm{~h})$. Excitation wavelength: $345 \mathrm{~nm}$; Emission wavelength: $490 \mathrm{~nm}$; $\mathrm{F}_{0}$ and $\mathrm{F}$ are fluorescence intensities of PB-COP1 in the absence and presence of Cs ion at $490 \mathrm{~nm}$. (b) Stern-Volmer plot of fluorescence quenching of PB-COP1 in the presence of Cs ion. (c) Photographs of PB-COP1 dispersions under ambient and UV lights ( $365 \mathrm{~nm}$ ) in the absence and presence of Cs ion $(50 \mathrm{ppm})$. 

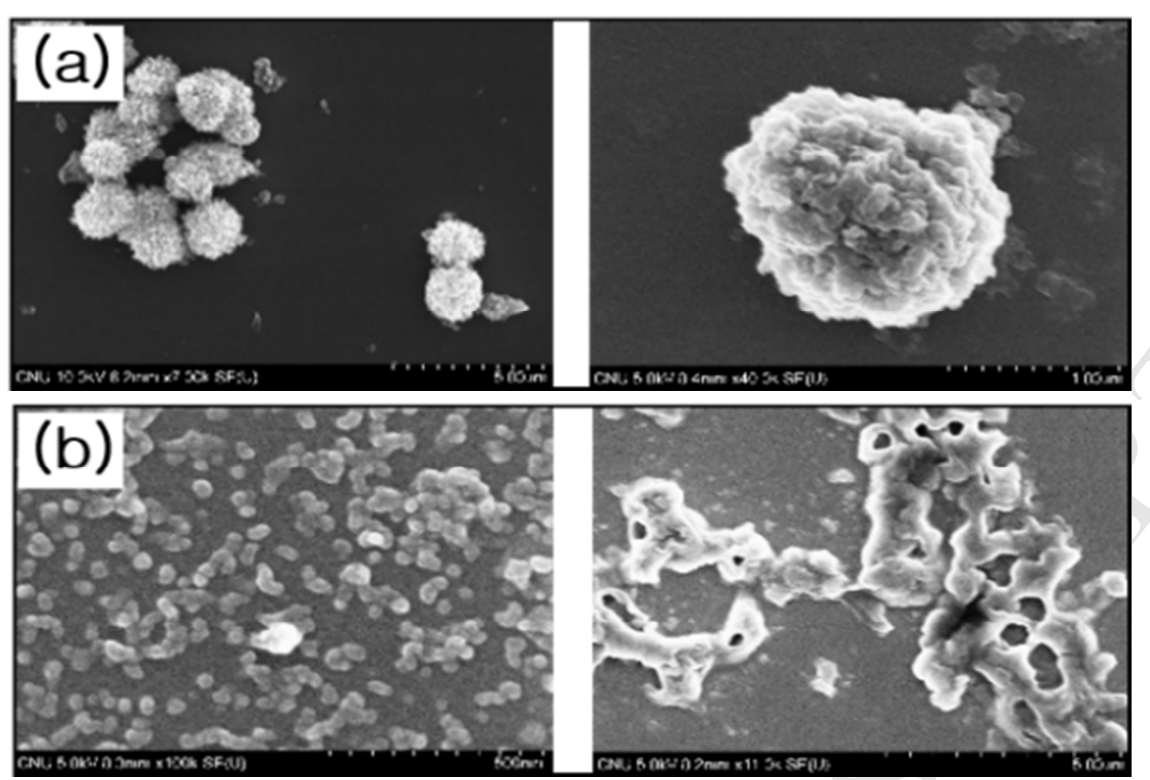

Fig. 4. SEM images of PB-COP1 (a) before and (b) after addition of Cs ion (50 ppm, $48 \mathrm{~h})$. 


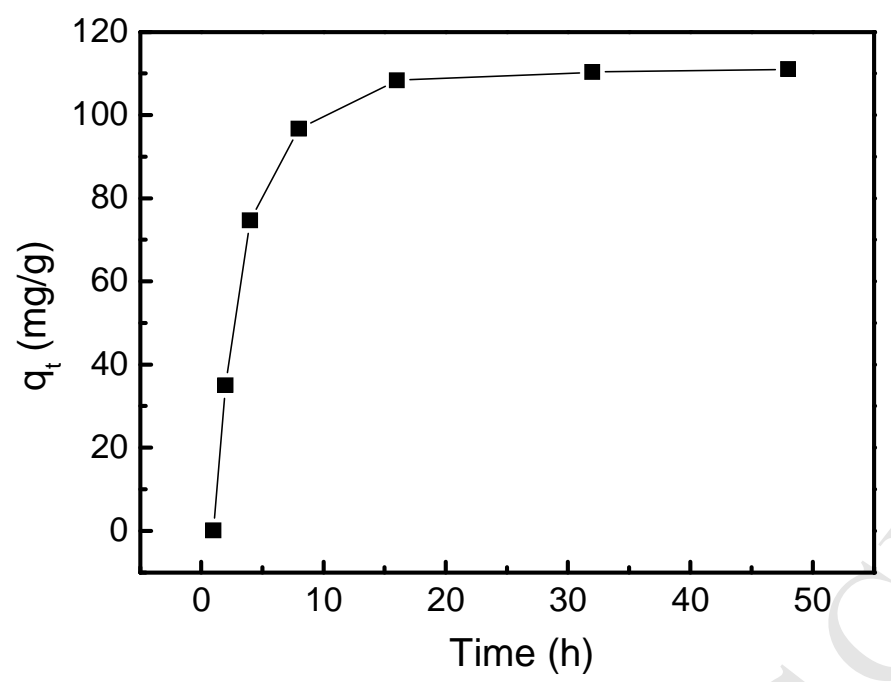

(a)

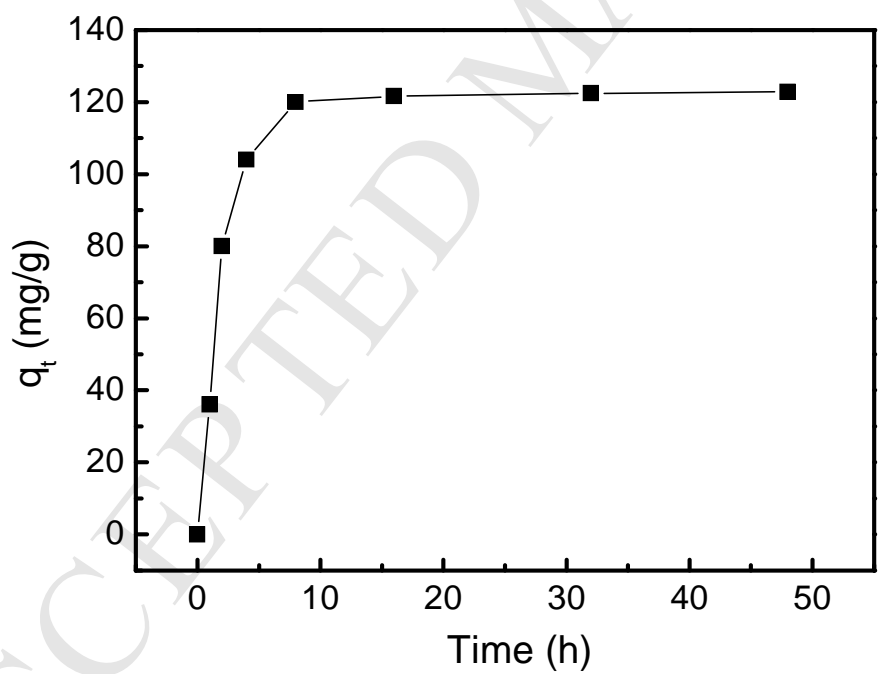

(b)

Fig. 5. Effect of exposure time on the adsorption of Cs ion with (a) PB and (b) PBCOP1. 
Table 1 Adsorption of Cs Ions by PB and PB-COP1

\begin{tabular}{ccccc}
\hline & $\begin{array}{c}\text { Initial } \\
{\left[\mathrm{Cs}^{+}\right]} \\
(\mathrm{ppm})\end{array}$ & $\begin{array}{c}{\left[\mathrm{Cs}^{+}\right] \text {in }} \\
\mathrm{PB} \\
(\mathrm{ppm})\end{array}$ & $\begin{array}{c}{\left[\mathrm{Cs}^{+}\right] \text {remained in }} \\
\text { the solution } \\
(\mathrm{ppm})\end{array}$ & Adsorption (\%) \\
\hline $\mathrm{PB}^{\mathrm{a}}$ & 50 & 33.4 & 16.6 & 67 \\
$\mathrm{~PB}-C O P 1^{\mathrm{b}}$ & 50 & 30.7 & 19.3 & 61 \\
\hline
\end{tabular}

${ }^{\mathrm{a}}[\mathrm{PB}]=0.03 \mathrm{mg} / \mathrm{mL}$

${ }^{\mathrm{b}}[\mathrm{PB}-\mathrm{COP} 1]=0.025 \mathrm{mg} / \mathrm{mL}$ 
Table 2. SEM images of PB-COPs.

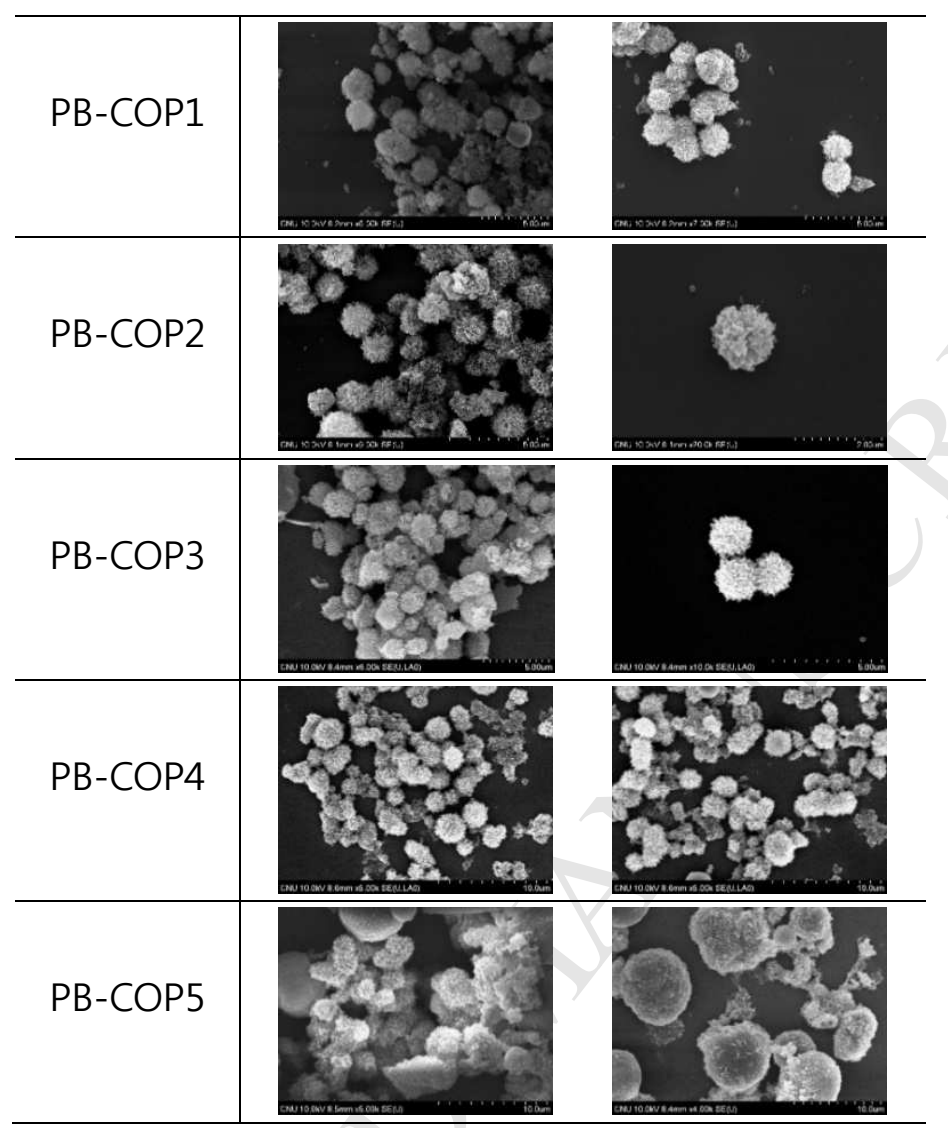

$\star$ Scale bars in PB-COP1, PB-COP2 and PB-COP3 were of $5 \mu \mathrm{m}$. Scale bars in PB-COP1, PB-COP2 and PB-COP3 were of $10 \mu \mathrm{m}$. 


\section{Highlights}

- A hybrid material was prepared with coordination polymer (COP) and Prussian blue (PB).

- COP was prepared by ionic interaction between $\mathrm{COOH}$ of organic molecules and $\mathrm{Zn}$ ions.

- The hybrid materials could remove efficiently Cs ions via adsorption on PB.

- The fluorescence of COP in hybrid materials also decreased upon exposure to Cs ions. 